\title{
НАУЧНЫЙ ДЕБЮТ
}

DOI: https://doi.org/10.31992/0869-3617-2020-29-10-153-160

\section{Политическая миссия университета: ретроспективный взгляд}

Ауковенков Сергей Геннадьевич - аспирант. E-mail: lukovenkovsergei@yahoo.com Российский государственный гуманитарный университет, Москва, Россия Адрес: 125993, Москва, Миусская пл., 6

Аннотация. Академическое пространство в различных своих манифестачиях с ранней истории человечества занимает почётное место в структуре сочиума, систематизируя многообразие опьта о внешнем и внутреннем мирах человека. В то же времл образовательнал среда формулировала разнообразнье способь осмьсления и взаимодействия человека с миром, вступая в борьбу с альтернативными системами, причём борьба эта не обязательно носила интеллектуальный и полемический характер. Мало что изменилось в статусе академии и в эпоху свершившейся изифровой револючии, в том числе в отношении дисииплинарньх практик академии как инструмента надзора и сочиального сортирования - двух важньх элементов власти. В статье предпринимается попьтка осмьсления университета В роли особого культурно-политического пространства, используемого для вьполнения надзорньх и фильтрачионньх задач как способа сочиального воспроизводства. На примере колониальньх колледжей в США рассматривается способность университета быть, с одной стороны, надзорным органом, а с другой-опорой культурного сдвига, в том числе $B$ цичрровую эпоху.

Ключевые слова: история образования, университет и общество, колониальнье колледжи США, Паноптикон, воспитание, контроль, педагогика, иирровизачия образования

Аля изитирования: Ауковенков С.Г. Политическая миссия университета: ретроспективный взгляд // Высшее образование в России. 2020. Т. 29. № 10. С. 153-160.

DOI: https://doi.org/10.31992/0869-3617-2020-29-10-153-160

\section{Введение}

Социально-философская мысль всегда с особым трепетом и интересом подходила к изучению практик, обеспечивающих культурную преемственность, воспроизводство и сохранность общественного организма. Как возможно, чтобы большое число людей, разделённое экономическими, классовыми, политическими, религиозными и прочими факторами, тем не менее представляло собой некое единство, идентифицируя себя по групповому признаку и обладая социальной памятью, связывающей поколения в целое, пусть даже на базовом уровне: «мы - люди», «мы - европейцы», «мы - христиане», «мы - коммунисты»? Внимание к механизмам самовоспроизводства социального порядка сопровождается желанием понять возможности трансформации социокультурного пространства без необходимости насильственных и активно-репрессивных мер. Философы и интеллектуалы разных эпох - от Платона до идеологов Просвещения и мыслителей сегодняшнего дня - возлагали и продолжают возлагать большие надежды на правильно сформированный процесс обучения, видя именно в нём эффективный инструмент для построения пусть не идеального, но, во всяком случае, разумного и устойчивого общества. Закрепляя значи- 
мость образования для жизни государства, Платон в «Законах» пишет: «невежественным гражданам нельзя поручать ничего относящегося к власти; их должно поносить как невежд, даже если они и горазды рассуждать и наловчились во всевозможных душевных тонкостях и извивах» [1, с. 141]. А Аж. Аьюи, один из виднейших философов североамериканского континента, в работе 1916 г. «Аемократия и образование», говоря о процессе обучения, утверждает: «без того, чтобы люди учились сами и учили других, общественная жизнь не может протекать, т.е. сам процесс жизни сообща имеет образовательное значение» [2, с. 11].

\section{Университет и дисциплинарные практики}

Об образовании, воспитании, взращивании человека можно говорить по-разному. Можно изучать эти процессы как проявления необходимого для выживания человека навыка передачи опыта. Можно анализировать смену парадигм, то есть представлений о том, как и что должно быть передано в воспитании от субъекта к субъекту, в зависимости от культурных, религиозных и технологических особенностей выбранной эпохи. При этом для социально-философской теоретической и практической мысли интерес представляют институционализированные модели образовательно-воспитательного процесса, их форма, взаимосвязь с другими частями социального организма, возможности поддерживать и видоизменять социальный, политический или культурный фон, царящий в социуме. Многообразие данной проблематики сводимо к одной охватывающей исследовательской теме - определение сущности образовательных институтов, в частности Университета как системы, в которой воспитание, образование и научная активность тесным образом сплетены, понимание университета как одного из горнил культурной жизни. М.А. Розов предлагает посмотреть на университет как на «социокульурную эстафету - волну», где, «воспроизводя образцы живой речи, мы учимся говорить, на базе образцов рассуждения усваиваем правила логики, находясь в среде других людей, перенимаем формы их поведения, элементарные трудовые навыки, типы реакций на те или иные события» [3. с. 232]. Подобного рода задачи - не плоды праздного научного интереса. Институты образовательной сферы исполняют, пусть и не единовластно, задачу сцепления общества через формирование правил коммуникации, остающихся с индивидом даже после окончания учёбы и забвения полученных практических и профессиональных навыков. Изучение способов существования этих институтов тем самым не только даёт понимание их исторического пути, но и может снабдить инструментарием для своевременного опознавания переходных периодов, связанных зачастую с внедрением новых технологических потенциалов, и, возможно, позволит активно влиять на изменения, а не только реагировать post factum.

Говорить о «чистой форме» (Платон) университета - значит говорить и о его социальной миссии, о том, успешно или нет он справляется с ней, актуальна она до сих пор или сошла с повестки истории. Это хорошо видно на примере критики системы современного высшего образования, проведённой Биллом Ридингсом в монографии под названием «Университет в руинах». «Уже не понятно, ни каково место Университета в обществе, ни какова истинная природа этого общества, и интеллектуалы не могут позволить себе игнорировать данное изменение институциональной формы Университета», [4, с. 22] - формулирует Ридингс проблему состояния Университета, видя одну из причин в «американизации» высшего образования как следствия глобализационных процессов и «смерти» классического университета, существование которого немыслимо без связи с судьбами национальных государств.

Каким образом Университет исполняет регулятивную социальную функцию для 
общества? Сферу образования, включающую институты от детских садов до вузов, можно представить в качестве одного из инструментов регулирования «человеческого капитала», если угодно - как «фабрику» и одновременно пункт «проверки качества», поскольку поступление в учебный институт требует от человека соответствия некоторому цензу - финансовому, интеллектуальному, культурному и т.д. - с последующим систематичным его подтверждением посредством экзаменации, пользуясь языком Фуко, права на участие в социальной деятельности. Рассматривая механизм педагогического воздействия в его значении для поддержания социального порядка, французские социологи Пьер Бурдьё и Жан-Клод Пассрон пишут, что «как символическое насилие, педагогическое воздействие может производить свой, собственно педагогический, эффект, только если даны социальные условия принуждения и внушения, т.е. существуют силовые отношения, не входящие в формальное определение коммуникации» [5, с. 24]. Под «силовыми отношениями» можно понимать не только, к примеру, установленную в месте воспитания иерархическую структуру подчинения, но и материальные грани существования, такие как архитектурные особенности или финансовое состояние института. Из суммы идейных и материальных аспектов формируется как миссия и роль университета, так и механизмы дисциплинарного контроля. Такая сложная структура ведёт к тому, что Университет не только оказывается важным механизмом для удерживания общества в единстве на протяжении смены поколений, но и существует в ситуации, когда изменения в одном «кирпиче» системы могут привести к изменениям, которые повлияют не только на Университет, но и на общество, в котором он существует, а возможно - на весь мир.

Согласно статистическим прогнозам, ожидается, что в 2020 г. в США порядка 20 миллионов человек пополнят стены общественных и частных высших учебных заве- дений ${ }^{1}$. Удовлетворению потребностей столь большого числа людей требуется масштабная инфраструктура, «построенная» из преподавательского состава, персонала, технического оснащения и необходимых экономических условий, играющих большую роль Аля формы и деятельности всего механизма. В силу подобной необходимости университеты не способны к осуществлению автономии в полной мере, тем самым вовлекаясь в проблемную среду остального социума. Исходя из этого сложно представить, чтобы образовательные институты могли быть сведены исключительно к профессиональной подготовке и осуществлению научной деятельности: связь с политико-социальными и культурными процессами, происходящими во «внешнем мире», требует не только реакций на внешние стимулы, но и порой активного участия в актуальных событиях. Склонность к повышенной реактивности на внешние «раздражители», свойственная Университету, и делает его центральным предметом для понимания того, как академическая среда связана с рождением, формированием и поддержанием жизни социума и его культуры.

\section{Из истории образовательной системы США}

В качестве эмпирической базы можно обратиться к истории возникновения высшего образования в Соединённых Штатах Америки в эпоху колониальной зависимости от Великобритании. Поскольку в рамках небольшой статьи едва ли возможно охватить все тонкости и нюансы исторического пути американских вузов, обратимся к одной стороне вопроса, а именно - к влиянию архитектуры на существование и функционирование колледжей. Это интересно не только в историческом смысле, но также в смысле возможной әкстраполяции опыта прошлого на события в секторе об-

1 По данным статистического портала Statista: https://www.statista.com/statistics/183995/uscollege-enrollment-and-projections-in-public-andprivate-institutions/ 
разования современности, которые плотно связаны с возросшим влиянием информационных технологий на процесс образования и способы существования университетов в цифровом мире. В философском и социологическом отношении эти аспекты существования Университета связаны одной большой темой влияния технологий на бытие человека и социума в мире: как технологическое может быть превращено в дисциплинарное.

Установка дисциплинарной власти - нормализация субъектов под представления доминирующей системы ценностей через тотальный охват властью проявлений жизнедеятельности подчинённого субъекта [6, c. 64]. Самым известным образцом подобной системы, пусть и не осуществлённым в жизни, может выступить «Паноптикон» Иеремии Бентама, являющийся пространством, где надзор при помощи архитектуры возведён в абсолют и превращён в своеобразное техническое средство. Важно, что Паноптикон - это не исключительно тюрьма, но и фабрика, мастерская, больница, школа и многие другие социальные институты, где осуществляется процесс воспитания и управления над большим или малым количеством людей и производство общей социальной идентичности, а также устранение «вредоносных» элементов. Чем же может быть полезен проект английского юриста и политического радикала для изучения прошлого, настоящего и будущего Университета и институционального образования в целом? Бентам постулирует, что предназначение подобной архитектурной авантюры состоит во внедрении экономически выгодных и эффективных практик контроля, которые будут действенны вне зависимости от задач, будь то контроль над заключёнными или поддержка дисциплины учащихся [7, с. 40]. Паноптикон - яркая иллюстрация того, как материальные аспекты социальных институтов могут служить в качестве некой техно-инструментальной составляющей политической или социальной программы, будь она консервативна или революционна по своей природе.

История американского высшего образования начинается до образования США как независимой подитической единицы с появления колледжа, позже университета, имени Ажона Гарварда в 1636 г. Эпоха колониальной зависимости североамериканских штатов характеризуется желанием власти сформировать культуру не в последнюю очередь через систему высшего образования, которая выступала бы объеАиняющим инструментом, способным преодолевать колоссальные географические пространства, разделяющие колониальный и британский миры. Колониальный период заложил фундамент системы высшего образования будущего государства в целой плеяде колледжей, среди которых такие громкие имена, как Йель, Принстон, Колумбия, Рутгерс и другие. Эти колледжи были не только местом обучения, но и аренами, где шли процессы социально-политического формирования колониального общества, в том числе в период борьбы за независимость. На время войны кампусы превращались в госпитали, казармы и политические трибуны. Очевидно, что этого мало для того, чтобы судить о колледжах как о незаменимых инструментах передачи знания или как о важных социальных инструментах, способных менять образ целого общества. Тем не менее историк американского образования Ажон Телин ${ }^{2}$ пишет: «Исторические колледжи, основанные в колониальную эпоху, занимают особое место в нашей национальной памяти» [8, с. 1]. Чем же они заслужили столь высокую оценку и какие функции, кроме образовательных, они осуществляли?

\footnotetext{
${ }^{2}$ Ажон Телин (John Thelin) - профессор Колледжа образования Университета Кентукки и исследователь в области истории и политики образования, автор шести монографий и статей для крупных журналов о высшем образовании, среди которых Journal of Higher Education, History of Education Quarterly и др.
} 
Ранние колледжи были тесным образом связаны с английской культурной традицией. Учреждения высшего образования колониального периода обретали жизнь в основном благодаря финансовой поддержке британского правительства, в том числе из колониальных налоговых сборов, или за счёт меценатов. Родоначальники американского высшего образования ориентировались на английский университетский опыт коллегиального образа жизни студентов и профессоров, соединяющего в единое целое образовательные, научные и бытовые аспекты жизнедеятельности. Подобная система подкреплялась особым положением английских университетов в архитектурном и юридическом смыслах. Британские колледжи в составе университетов-федераций сохраняли большую степень автономии, гарантированную королевскими хартиями, независимым финансированием, идеалами самоуправления - университет обладал правом присуждать степени, при этом не вмешиваясь во внутренние дела колледжей. Автономия распространялась и на планировку кампусов, обеспечивающую все нужды поселенцев, вследствие чего академическая среда «отчуждалась» до определённой степени от социальных и политических проблем, происходящих за университетскими стенами. Американские основатели колледжей стремились к «пересадке» подобного рода идеалов на колониальную почву, однако экономические трудности внесли коррективы в задуманное: отсутствие достаточных и стабильных финансовых источников не позволило осуществить планы в полной объёме. В особенности это коснулось архитектурной стороны: отсутствие необходимых ресурсов не позволило воссоздать устройство кампусов английских колледжей с их автономной и замкнутой экосистемой [8, с. 9]. Впрочем, колониальное правительство со скепсисом относилось к независимости администрации и преподавательского состава, что в итоге привело к формированию системы, в рамках которой возник институт сильного колледжского президента, отвечающего не перед советом факультетов, а перед советом попечителей. По замечанию Телина, данная модель - это «наследие колониальных колледжей, которое определяет и формирует высшее образование в Соединённых Штатах вплоть до этого дня» [8, с. 12] В сумме всё перечисленное - это важные факторы, задавшие векторы дальнейшего пути развития американского образования и оформления политических и социальных идеалов государства.

Основанные под покровительством короны, колледжи были призваны культивировать принципы «англофилии», чему способствовала монополия на распространение знания: до определённого времени информация циркулировала в обществе преимущественно посредством устного обучения. Образовательный сектор должен был удерживать политические и культурные элиты колоний в орбите английской цивилизации. Важная составляющая деятельности колледжей - воспитание молодого поколения из местной аристократии и воспроизводство политических и административных элит. Хотя колледжи и не могли полностью осуществить общинную модель, образовательный процесс стремился, пусть и не повсеместно, соответствовать представлениям о необхоАимости постоянной вовлечённости студентов и профессоров в общее дело, состоящее из общежития и обучения, ориентированного на овладение навыками аргументации и публичной деятельности. Аисциплинарная система по части наказаний работала по принципу социального сортирования: провинившийся студент ссылался из места обучения, исключаясь из академической социальной сети. Колониальные колледжи сложно назвать «открытыми» и «демократичными» по той причине, что поступление в колледж было доступно далеко не каждому. Как пишет Телин, «колледж был консервативным учреждением, которое было существенно необходимо для передачи относительно устоявшегося социального порядка» [8, с. 25]. 


\section{Заключение}

История становления британских колониальных колледжей подтверждает фундаментальную идею Паноптикона, гласящую, что правильно обустроенное пространство - архитектурное и идейное - это сложное техническое приспособление, которое может быть эффективно использовано для трансформации социального порядка или укрепления оного без применения насилия лишь благодаря методам вовлечения полезных и исключения неугодных элементов. На примере истории колониальных колледжей можно видеть, как на политические и культурные процессы влияют, казалось бы, мало связанные с контролем и властью вещи, такие как архитектура, особенности учебного процесса и порядки общежития.

Стоит попытаться философски осмыслить политические и социально-культурные возможности, которые открываются перед Университетом и другими институтами образования в ситуации, когда процесс социального сортирования и фильтрации может быть осуществлён в куда более эффективных и существенных масштабах. Как демонстрирует история, техническое может вести к неожиданным последствиям. Вопрос о влиянии на Университет и в целом на процесс образования технических новшеств особенно актуален в эпоху, когда цифровые технологии проникли чуть ли не во все аспекты жизнедеятельности человека, носящего с собой, как остроумно заметил Зигмунт Бауман, «персональный паноптикон» [9, с. 59]. Сегодня социальные институты сферы образования также прошли через процесс дигитализации, что позволило не только расширить охват населения через введение дистанционных форм обучения, но и внести существенные изменения в отношения университета с внешним миром. С течением времени дигитализация образования, вероятно, будет усиливаться и принимать всё более радикальные формы. Однако само по себе устранение жёсткой привязанности к географической и социальной среде логически не ведёт к тому, что академическое пространство будет двигаться к устранению границ, создавать здоровую научную атмосферу или перестанет быть транслятором идей тех, кто обладает не столько монополией на знание, сколько контролем за техническим оснащением, поскольку «система образования функционирует подобно эпистемологической матрице, “отбивающей” (формующей) Аля всего остального мира дискурсы развития и модернизации» $[10$, с. 126$]$. Эволюция колледжей эпохи колониализма показывает, что технологический аспект способен существенно повлиять на финальный результат образовательной деятельности. Немецкий теоретик культуры южнокорейского происхождения Хан Бюн-чхоль, характеризуя современную информационную культуру, утверждает, что «полное взаимодействие и коммуникация посредством цифровых приспособлений не облегчают встречу с Аругими. Скорее, они служат уклонению от тех, кто чужд и отличен, занимаясь поиском тех, кто похож и мыслит так же, гарантируя тем самым, что горизонт нашего опыта будет лишь сужаться» [11, с. 7]. Касаясь темы воздействия цифровых технологий, в том числе в их надзорно-дисциплинарной модальности, можно провести параллель с тем, какую роль сыграл технический фактор в определении способа бытия колледжей, впоследствии ставших культурными центрами США, а также их влияния на политические и социальные процессы.

События, связанные со вспышкой коронавирусной инфекции, продемонстрировали, что уход сектора образования в онлайнпространство - не утопические мечты, а уже вполне реальная возможность в том смысле, что существует техническая база, позволяющая уже сейчас переносить часть процесса образования из аудиторий кампусов в домашние компьютеры. В мае 2020 г. в сеть попало служебное электронное письмо, адресованное сотрудникам Кембриджского университета, сообщающее, что все университетские лекции 2020/2021 учебного года 
будут проводиться удалённо, пусть и с сохранением требований «реального» присутствия на семинарах, мастер-классах и т. п. ${ }^{3}$ И несмотря на то, что в настоящий момент частичный переход процесса образования в цифровое пространство не представляет Аля Университета серьёзной опасности, в силу непривычности такого рода метода и отсутствия гибкой инфраструктуры необходимо иметь в виду реальность сценария, при котором Университет приобретёт скорее «виртуальный», нежели «реальный» статус в жизни социума. Перед исследователями и теоретиками стоит амбициозная и серьёзная задача по осмыслению настоящего и будущего, которое готовит для образования цифровая революция, а также для морали, идеалов коммуникации и прочих социальных структур, тесно переплетённых друг с другом, и представленных в мире под именем Культуры.

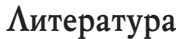

1. Платон. Собрание сочинений в 4 т. Т. 4 / Пер. с Аревнегреч.; Общ. ред. А.Ф. Аосева, В.Ф. Асмуса, А.А. Тахо-Годи. М.: Мысль, 1994.830 с.

2. Аъюи Аж. Аемократия и образование / Пер. с англ. М.: Педагогика-Пресс, 2000. 384 с.
3. Розов М.A. Что такое теория социальных эстафет // Эпистемология и философия науки. 2017. № 1. DOI: 10.5840/eps201751121

4. Ридингс Б. Университет в руинах / Пер. с англ. А.М. Корбута. Минск: БГУ, 2009. 248 с.

5. Бурдъё, П. Воспроизводство: элементы теории системы образования / Пер. Н.А. Шматко. М.: Просвещение, 2007. 267 с.

6. Фуко М. Психиатрическая власть: Курс лекций, прочитанных в Коллеж де Франс в 1973-1974 учебном году / Пер. с фр. А.В. Шестакова. СПб.: Наука, 2007. 450 с.

7. Bentham Jeremy. Panopticon, or Inspection-house // The works of Jeremy Bentham, Volume Four. New York, 1962. P. 37-172.

8. Thelin J.R. A History of American Higher Education. Johns Hopkins University Press, 2013. $499 \mathrm{p}$.

9. Lyon D., Bauman Z. Liquid Surveillance. Hoboken, Wiley, 2013.184 p.

10. Ивахненко E. Российский университет перед лицом принудительных эпистем неоглобализма // Высшее образование в России. 2008. № 2. C. $122-129$.

11. Hoban W., Han B. The Expulsion of the Other. Hoboke, Wiley, 2018. 111 p.

Статья поступила в редакииию 03.04.20

После доработки 22.08.20

Принята к публикачии 10.09.20

\section{Political Mission of University: A Retrospective View}

Sergei G.Lukovenkov - Postgraduate student, e-mail: lukovenkovsergei@yahoo.com

Russian State University for Humanities, Moscow, Russia

Address: 6, Miusskaya sq., Moscow, 125993, Russian Federation

Abstract. Academic space in its different manifestations has been taking an honorable position in social structure from the earliest stages of the history of human civilization by systematizing multitude experiences of both external and internal world of humankind. At the same time, educational landscape was formulating the different ways of how to theorize about and interact with the world. Simultaneously, there was always combating with the alternative systems and, what is more, this struggle wasn't necessarily intellectual or polemical. Little has changed in how society perceives academy and its functions in the era of accomplished digital revolution, including its role as an instrument of surveillance and social sorting - these two important elements of power. In this article, an attempt is taken to comprehend University - and speaking broadly academic space as such - as a special kind of social and political field used to perform surveillance and social control. On the

\footnotetext{
3 По данным независимого студенческого новостного издания кембриджского университета Varsity: https://www.varsity.co.uk/news/19258
} 
example of colonial colleges in the USA, this article examines how University may serve as a surveillance mechanism on the one hand and as a mean of cultural transformation on the other hand, and what conclusions can be made regarding the present and the future of University in the digital era.

Keywords: history of education, University and society, colonial colleges, Panopticon, social control, pedagogy, digitalization of education

Cite as: Lukovenkov, S.G. (2020). Political Mission of University: A Retrospective View. Vysshee obrazavaniev Rossii = Higher Education in Russia. Vol. 29, no. 10, pp. 153-160. (In Russ., abstract in Eng.)

DOI: https://doi.org/10.31992/0869-3617-2020-29-10-153-160

\section{References}

1. Plato (2016). Laws, Book III. In: Schofield, M. (Ed.), Griffith, T. (Transl.) Cambridge Texts in the History of Political Thought. Cambridge University Press. (Russian translation and edition: A.F. Losev, V.F. Asmus, A.A. Takho-Godi, Moscow: Mysl' Publ., 1994, 830 p.)

2. Dewey, J. (1915). Democracy and Education: An Introduction to the Philosopby of Education. Columbia University, New York City. (Russian translation: Moscow: Pedagogika-Press, 2000, 384 p.)

3. Rozov, M.A. (2017). What is the Social Relay Theory. Epistemologiya i folosofiya nauki=Epistemology \& Pbilosopby of Science. Vol. 51, no. 1, pp. 230-239. DOI: 10.5840/eps201751121 (In Russ., abstract in Eng.)

4. Readings, B. (1997). The University in Ruins. Harvard University Press, 256 p. (Russian translation: M.A. Gusakovskiy (Ed.) A.M. Korbut (Trans.), Minsk: BGU, 2009. 248 p.)

5. Bourdieu, P., Passeron, J.-C. (1970). Éléments pour une théorie du système d'enseignemen. Paris, Les Éditions de Minuit, 283 p. (Russian translation by N.A. Shmatko, Moscow: Prosveshchenie, 2007. 267 p.)

6. Foucault, M. (2006). Psychiatric Power: Lectures at the Collège de France, 1973-1974. Palgrave Macmillan UK, 383 p. (Russian translation by A. Shestakov, St. Petersburg: Nauka, 2007. 450 p.)

7. Bentham, J. (1962). Panopticon, or Inspection-house. In: Bowring, J. The works of Jeremy Bentham, Vol. Four (Panopticon, Constitution, Colonies, Codification). New York: Russell \& Russell, pp. 37-172.

8. Thelin, J.R. (2013). A History of American Higher Education. Johns Hopkins University Press. $499 \mathrm{p}$.

9. Lyon, D., Bauman, Z. (2013). Liquid Surveillance. Hoboken, Wiley, 184 p.

10. Ivakhnenko, E. (2008). [Russian University in the Face of Coercive Epistems of Neo-Globalism]. Vysshee obrazovanie $v$ Rossii = Higher Education in Russia. No. 2, pp. 122-129. (In Russ.)

11. Hoban W., Han B. (2018). The Expulsion of the Other. Hoboke, Wiley. 111 p. 